\title{
Rosalía de Castro y su hijo Adriano. Génesis y desarrollo de un poema elegíaco
}

\author{
Lucía GARCíA VEGA \\ Universidad Complutense de Madrid \\ lugarvega@gmail.com
}

\begin{abstract}
RESUMEN
El presente artículo se articula en torno a dos importantes documentos inéditos, uno biográfico y otro bibliográfico, concernientes al siempre actual ámbito de estudio de la eminente escritora Rosalía de Castro (1837-1885). Satisfactoriamente somos los primeros en transcribir íntegra la partida eclesiástica de defunción de Adriano Martínez de Castro (1875-1876), penúltimo hijo del ilustre matrimonio formado por Rosalía de Castro y Manuel Martínez Murguía (1833-1923), fallecido a muy temprana edad en un infortunado accidente doméstico ocurrido en Santiago de Compostela. Asimismo damos a conocer el poema titulado “¡Hijo mío!”, publicado en Madrid en 1878, y que resulta ser un valioso hallazgo bibliográfico, puesto que todo apunta a que sea esta composición la versión original de una parte del texto lírico que comienza con "Era apacible el día" y que se incluyó en la edición príncipe de En las orillas del Sar (1884).
\end{abstract}

Palabras clave: Rosalía de Castro, poesía, Posromanticismo, literatura mujer siglo XIX, Manuel Murguía.

[Recibido, enero 2012; aprobado, junio 2012]

\section{Rosalia de Castro and her son Adriano. Genesis and development of an elegiac poem}

\begin{abstract}
This article is structured around two important unpublished documents, a biography and bibliography, concerning the ever-present field of study of Rosalia de Castro (1837-1885). Successfully transcribed are the first ecclesiastical death certificate Adriano Martinez de Castro (1875-1876), son of the illustrious junior marriage of Rosalia de Castro and Manuel Murguia (1833-1923), who died at very early age in an unfortunate accident at home occurred in Santiago de Compostela. Furthermore we present the poem "¡Hijo mío!", published in Madrid in 1878, and who happens to be a trove literature, since all indications are that this composition is the original version of the text of a lyric that begins "Era apacible el día" and was included in the first edition of En las orillas del Sar (1884).
\end{abstract}

Keywords: Rosalia de Castro, poetry, post-Romanticism, nineteenth-century women's literature, Manuel Murguia. 


\section{Contexto pretrágico (1874-1876)}

Tal vez una manera práctica de comenzar este escrito sea aludir a un aspecto escasamente tratado, y puede que de cierto rédito para el estudioso de la biobibliografía de Rosalía de Castro, como resulta ser el reclamo de la obra literaria de la insigne escritora en la prensa escrita. Así, en lo que compete al ámbito publicitario, no parece que vayamos desorientados al decir que el año 1874 semeja haber sido programado de forma similar a lo que hoy se entiende por una avispada campaña de marketing. A mediados de ese año dos conocidos periódicos gallegos anunciaban que "muy en breve verá la luz pública en Madrid un nuevo libro de Rosalía Castro de Murguía titulado Follas Novas" (El Diario de Santiago, 15/6/1874), publicación que "indudablemente añadirá un lauro mas á su bien reputada fama" (El Heraldo Gallego, 29/1/1874).

La realidad cronológica fue otra muy diferente a la del producto promovido, puesto que este texto lírico abandonó la oscuridad del taller tipográfico seis años después, si bien es verdad que el pronóstico promocional sobre el éxito que tendría el poemario fue superado con mucha amplitud y, con el tiempo, resultó ser una de las obras más ideográficas de la escritora compostelana.

Con todo, desde finales de 1874 una serie de acontecimientos adversos, personales y profesionales, marcaron las vidas de Rosalía de Castro y de su esposo, Manuel Martínez Murguía. El 18 de noviembre fallecía en Santiago de Compostela Juan Martínez Castro, padre del popular historiador. Con apenas un mes de diferencia, el 17 de diciembre moría en Madrid el compostelano Ramón Rúa Figueroa, gran amigo de Murguía y con el que mantuvo una estrecha relación epistolar dilatada en el tiempo ${ }^{1}$, aparte de ser un notable y simbólico eslabón de la cadena de contactos entre algunos de los intelectuales de la época.

Tampoco el año 1875 empezó con mucha fortuna laboral para el famoso matrimonio. El 20 de febrero Murguía era cesado como director del Archivo General de Galicia por no reunir las condiciones recomendadas por la legislación del ramo. Hoy, con la objetividad que la distancia cronológica suele dar, parece probable que detrás de esta versión autorizada y oficializada existiese una motivación de fácil entendimiento como fue la inestable coyuntura histórica ${ }^{2}$ e institucional ${ }^{3}$ de los años setenta.

\footnotetext{
${ }^{1}$ Según hemos podido verificar, desde agosto de 1866 las remisiones de cartas a Manuel Murguía fueron ininterrumpidas. Véase Barreiro \& Axeitos (2003, 2005).

${ }^{2}$ Con la restauración de la monarquía en la persona de Alfonso XII, Príncipe de Asturias e hijo de Isabel II, y la nueva Constitución de 1876 promulgada por el conservador Antonio Cánovas del Castillo (1828-1897), el panorama institucional sufrió cambios sustanciales. En el caso que nos ocupa, desde 1875 hasta 1879 el Ministerio de Fomento estuvo dirigido por Francisco Queipo de Llano (1840-1890), ejerciendo una política de corte canovista, al igual que sus predecesores Cristóbal Martín de Herrera (1831-1878) y Manuel Orovio Echagüe (1817-1883), por citar dos de los más cercanos dentro de este contexto cronológico. La línea de gestión llevada a cabo poco o nada tenía que ver con la existente cuando ocupaba este cargo ministerial el amigo de Murguía, Manuel Ruiz Zorrilla (1833-
} 
Por otra parte, semeja haber en general cierto consenso entre la heterogénea, quizás por ello también enriquecedora, crítica acerca de Rosalía y de Murguía al referir el dato sobre un viaje realizado por éste y la hija de ambos, Alejandra ${ }^{4}$, a Portugal en 1876 (Barreiro \& Axeitos 2000), si bien algún estudioso es más conciso y data esta estancia en abril de dicho año, "a donde había ido éste a estudiar el estilo manuelino" (Naya 1998: 150).

Poco tiempo antes de constituirse de nuevo el régimen monárquico español -30 de junio de 1876-, Manuel Murguía era repuesto de su cargo como Jefe de tercer grado, eso sí, esta vez en la sección de Bibliotecas y no en la de Archivos. De tal modo, el 5 de mayo se aprobaba su traslado a la Biblioteca Provincial y Universitaria de Valencia, nombramiento que se hacía público quince días más tarde en la Revista de Archivos, Bibliotecas y Museos: "Ha sido nombrado, por gracia, Jefe del grado tercero en la Sección de Bibliotecas, D. Manuel Murguía, que ántes había desempeñado igual cargo en la Sección de Archivos" (1876a: 177).

Sin embargo, la permanencia del célebre archivero en Valencia fue más breve de lo que a priori pudiera figurarse. Éste se habría presentado en su nuevo trabajo el 19 de junio, habitando en la ciudad del Turia hasta el 14 de septiembre (Estrada 1983), momento en el que era cesado de su recién estrenado cargo por no haber tomado posesión en el período estipulado por la ley a tal efecto. La Revista de Archivos, Bibliotecas y Museos informaba de este hecho:

Con fecha 14 del actual una Real órden ha declarado sin efecto el nombramiento de Jefe de tercer grado, en la Seccion de Bibliotecas, hecho a favor de D. Manuel Murguía, por no haberse presentado á desempeñar aquel empleo en el plazo señalado por vigentes disposiciones. Correspondió al concurso, en concepto nuestro, la plaza de Jefe de la Biblioteca de Valencia con que se agració al señor Murguía; y parece procedente que la nueva vacante se provea como debió proveerse ántes del dicho nombramiento (1876b: 304).

También en la edición del 24 de septiembre de 1876 del periódico valenciano Las Provincias se incluía la noticia siguiente:

Ha sido declarado cesante el gefe de nuestra Biblioteca provincial y universitaria D. Manuel Murguía, según parece por no haberse presentado a tomar posesión de su cargo en el plazo marcado por la ley. Esperamos que aclarada la mala inteligencia que ha dado lugar a esta cesantía, vuelva a ocupar su puesto el

\footnotetext{
1895), sobradamente conocido por su enemistad con Cánovas y su incesante oposición a Alfonso XII, lo que le costó vivir en el exilio.

${ }^{3}$ Son copiosos los Reales Decretos y las Reales Órdenes sobre supresiones, disoluciones, nombramientos, reorganizaciones en el Ministerio de Fomento, tanto en las secciones de Archivos como en las de Bibliotecas y Museos. Véase Fernández Bajón (2001).

${ }^{4}$ Se trata de la primera hija del matrimonio, nacida en 1859 en Santiago de Compostela. Falleció en 1938 en A Coruña.

${ }^{5}$ Hay una publicación anterior del mismo autor (1974) y que insertamos en la bibliografía de este artículo.
} 
ilustrado bibliotecario que tan gratos recuerdos ha dejado entre las personas estudiosas en los pocos meses que ha permanecido en Valencia.

Otro sedimento de la rotativa de aquel tiempo que hemos podido rescatar de las hemerotecas es el relativo a una estancia de Murguía en Madrid a comienzos de octubre de 1876, según recogía un periódico madrileño de manera escueta: "Ha llegado á Madrid el distinguido historiador gallego D. Manuel Murguía" (El Imparcial, 2/10/1876).

\section{Adriano Martínez de Castro, motivo poético}

Por desgracia y al contrario de lo que comúnmente la lógica puede indicar, Rosalía de Castro y Manuel Murguía sobrevivieron al sexto de sus hijos. Nacido en Santiago de Compostela el 20 de marzo de 1875, fue bautizado el 10 de abril de ese mismo año con los nombres de Adriano Honorato Alejandro. A falta de unos días para cumplir el año y medio de vida pereció a consecuencia de una caída fortuita en la vivienda número 17 de la calle de la Senra en Santiago de Compostela, casa alquilada que ocuparon Rosalía, sus hijos y, de forma intermitente, su esposo.

Siguiendo las pautas de lo que se entiende por racional, la documentación generada sobre Adriano es muy escasa, a lo que habría que añadir la presencia, casi podría decirse que permanente, de un nimbo enigmático y no pocas veces adulterado en cuanto a la biografía de su madre se refiere. Por ello, cada noticia colonizada y rescatada al y del olvido, respectivamente, parece venir ataviada con un simbólico tinte de lo insólito, en su acepción de suceso extraordinario, claro está.

La primera alusión oficial que la crítica reveló sobre Adriano fue un extracto del padrón de habitantes de Santiago de Compostela alusivo al año 1875, en el que uno seguido de otro se leían los nombres de todas las personas que habitaban la casa de la calle de la Senra, aspecto de una consideración irrebatible "por ser trozo interesante de pretérita vida, íntima y doméstica" (Moar 1920). De este censo, rubricado por Murguía el 19 de agosto de 1875, este crítico recogía las precisiones biográficas de "Adriano. 20 Marzo 75: 6 meses" y añadía que "por fallecer no está en el grupo fotográfico que el 84 hizo esta familia" (Moar 1920), haciendo mención explícita a la conocida foto familiar realizada en el exterior de la vivienda de A Matanza (Padrón, A Coruña), espacio doméstico mitificado en el que la escritora expiró y que en la actualidad es su Casa-Museo.

A este provechoso testimonio dado a conocer en el primer cuarto del siglo XX le siguió la publicación de las no menos significativas partidas civil y eclesiástica de nacimiento y de bautismo, respectivamente, de Adriano (Bouza 1962).

Hoy somos nosotros los que tenemos la honorable ocasión de mostrar en estas líneas una primicia referente a este hijo de Rosalía, lo que se traduce en dar un paso en firme y avanzar un poco más en el estudio de lo que pudo haber sido la biografía de una de las grandes escritoras universales del siglo XIX. 


\subsection{Documento biográfico inédito. Inscripción eclesiástica del fallecimiento de Adriano}

A continuación transcribimos literalmente la partida de defunción de Adriano y que hasta la fecha se desconocía:

Adriano Martínez. En el cementerio general de la ciudad de Santiago, provincia de la Coruña, en la noche del día cuatro del mes de noviembre, año de mil ochocientos setenta y seis se há dado sepultura eclesiástica al cadáver del parbulo llamado Adriano Martínez Castro, de edad de año y medio, bautizado en esta parroquia de Sta. Susana; ha muerto á las tres de la tarde del día anterior en la calle de la Senra numero diez y siete primer piso, hijo legitimo de Dn. Manuel, y de D. ${ }^{a}$ Rosalía, de esta vecindad y para que conste lo firmo como párroco de esta sobredicha. Julián de Castro (rúbrica) ${ }^{6}$.

En consecuencia, a partir de ahora conviene validar la precisión cronológica veraz de nombrar el día tres - y no el cuatro, como se hacía hasta ahora - de noviembre de 1876 como la data fatídica en la que murió Adriano, al que se le dio sepultura al día siguiente en el cementerio general compostelano y que, por aquel entonces, estaba ubicado en Santo Domingo de Bonaval ${ }^{\dagger}$.

En este sentido, en la mayoría de los distintos e indispensables estudios críticos sobre la escritora aparecidos desde la segunda mitad del siglo $\mathrm{XX}^{8}$ se había ido asumiendo la fecha del 4 de noviembre como el día real de la muerte de Adriano, Bouza (1962), Carballo (1964; 1979), Pociña \& López (1991, I; 2000), Alonso (2000), a excepción de Mayoral que comentaba con proporcionada cautela que el fallecimiento fue "un día de noviembre de 1876" (1986: 120).

Por nuestra parte, sospechamos que, al desconocerse la partida de defunción que aquí incluimos, el error habría podido partir de la última hija de Rosalía de Castro en desaparecer, Gala ${ }^{9}$, al realizar unas declaraciones ${ }^{10}$ que se publicaron en el dia-

\footnotetext{
${ }^{6}$ Archivo Histórico Diocesano de Santiago de Compostela. Parroquia de Santa Susana.

${ }^{7}$ Aquí también fue enterrada Teresa de Castro y Abadía (1804-1862), madre de la escritora y, posteriormente, la última de las hijas de Rosalía de Castro y Manuel Murguía, llamada Valentina y que nació muerta en 1877. Los versos del poema "¡Adios!" de Follas novas (1880), "Santo Domingo, en donde canto eu quixen descansa, / vidas da miña vida, anacos das entraña" (Castro 1993: 2, 289), estarían ratificando la veracidad de luctuosos episodios biográficos de la escritora. Asimismo en el edificio que había sido convento de Santo Domingo descansan sus restos desde 1891, en el conocido como Panteón de Gallegos Ilustres.

${ }^{8}$ No ocurre así en otros discursos críticos anteriores - por otra parte, situación sorprendente, puesto que han sido parte de la facción biográfica oficial de la escritora durante largo tiempo- $\mathrm{y}$ en los que las variaciones cronológicas e incluso las alusiones a uno u otro hijo son desacertadas. Así se puede leer que en 1875 nacía el deseado hijo varón (Besada 1916) o que a Rosalía le sorprendía el nacimiento de uno de sus hijos en 1875 en Lestrobe (Carré 1926-1927), si bien en ambos casos se confunde el nacimiento de Adriano con el de otro hijo varón del renombrado matrimonio.

${ }^{9}$ Junto a su gemelo Ovidio, éste reconocido pintor, había(n) nacido en las conocidas como Torres de Hermida de Lestrobe (Dodro, A Coruña) en 1871. Falleció en A Coruña en 1964.

${ }^{10}$ En 1949, a raíz de una fractura de pierna, Gala estuvo ingresada en una clínica coruñesa, en donde hacía esas revelaciones biográficas. Véase Roldán (1949).
} 
rio compostelano La Noche. Así se recogía en un interesante trabajo de BouzaBrey, quien citaba precisamente de la fuente de esas informaciones dadas por Gala:

Eran las tres de la tarde del día cuatro del melancólico mes de Difuntos, cuando Adriano murió de desgracia. El ama de Adriano (...) había colocado al niño sentado sobre una mesa, y, cayó de espaldas la criatura, con tal mala fortuna que falleció, al cabo, con torturante agonía (Bouza 1962: 379).

Continuaba Bouza comentando al respecto que la tragedia de Adriano fue llevada con bastante discreción para evitar una divulgación negativa de la noticia que pudiese perjudicar a cualquiera de los cónyuges. Es quizás la solución dada por este crítico la que más se ajustaría a lo que en realidad debió de ocurrir, toda vez que se certificó una difteria como causa de la muerte de Adriano, una enfermedad bastante contagiosa y frecuente en la población infantil de aquellos años, lo que, en buena parte, explicaría que en la partida de defunción eclesiástica se omitiese este matiz sobre la inhumación, ésta realizada "en la noche del día cuatro de noviembre".

Esta contribución primordial al ámbito de estudio biográfico de Rosalía la completamos con otra cuestión que semeja ser esclarecedora. Si es cierto, que no tiene por qué no serlo, lo que se publicó en un diario compostelano, entonces se estaría en condiciones de certificar que la escritora no estaba acompañada por Manuel Murguía ni el día de la defunción ni tampoco el del sepelio, éste realizado poco menos que en la clandestinidad. Con fecha 6 de noviembre de 1876 El Diario de Santiago en la Sección local incluía la escueta noticia "Ha llegado á esta ciudad el conocido escritor gallego Sr. D. Manuel Murguía", lo que obviamente le estaba situando esos desdichados días del tres y cuatro de noviembre en algún lugar que no era Santiago de Compostela.

Tuvieron que transcurrir los años para que Murguía hiciese una mención pública a su hijo Adriano, al recordar los momentos más tristes vividos al lado de su esposa, ésta ya finada en el momento de declarar lo siguiente:

Solos nos dejó la madre querida, y solos también aquel hijo amadísimo, que no vivió más que el tiempo necesario para hacer en nuestro corazón eterno el recuerdo, inconsolable la pérdida. Entre estos dos sepulcros, todo un mundo de contrariedades (Murguía 1886:181-182).

Mas Rosalía no pudo silenciar la aflictiva pérdida de su hijo durante tanto tiempo, dando a conocer literariamente su muerte dos años después de ocurrir, en concreto dedicándole un poema en 1878 y que tituló “¡Hijo mío!” del que nos ocupamos en el epígrafe siguiente. 


\section{Génesis y desarrollo de un poema elegíaco}

Conviene recuperar la figura del periodista y escritor algecireño Manuel Ossorio y Bernard ${ }^{11}$ (1839-1904), quien, entre las muchas empresas literarias acometidas a lo largo de su vida, fue el responsable de la edición del Almanaque de los niños para 1879, una publicación que el azar, a veces antojadizo, ha convertido en parte indisoluble de este apartado.

Este Almanaque, en su segundo año de existencia, acogió entre sus páginas el poema que Rosalía tituló “¡Hijo mío!”, por lo que, mientras no se demuestre lo contrario, esta colaboración habría sido la semilla que posibilitó la gestación lírica durante seis años de la elegía que la afligida madre le dedicó a su infortunado hijo Adriano. Con posterioridad la propia poeta fue realizando varias versiones de esta composición hasta conseguir la fórmula definitiva que finalmente fue incluida en el poemario En las orillas del Sar, en concreto integrándola en el escrito lírico que se inicia con el verso "Era apacible el día".

Conforme a algún anuncio ${ }^{12}$ que hemos podido exhumar de las hemerotecas, la publicación aquí señalada se promocionó desde la primera quincena de octubre de 1878. Conocemos también que este segundo número ${ }^{13}$ se editó en un volumen en $8^{\circ}$ y que su precio fue de 2 reales en toda España.

En cuanto a aspectos formales de esta edición parece apropiado mencionar algún detalle. Si se tiene el ejemplar delante, llama la atención la disposición nominal de los autores. Los nombres de las tres únicas mujeres colaboradoras ${ }^{14}$ están

\footnotetext{
${ }^{11}$ Es imposible referir aquí la ingente producción textual de Ossorio. No obstante, sí conviene aludir, aunque sea de modo sucinto, a sus labores de director y redactor de varios periódicos, tal y como resultan ser La Idea, El Noticiero de España, La Ilustración Católica, la Gaceta de Madrid, el Diario de Avisos, Don Quijote, La Correspondencia de España, El Contemporáneo, la Gaceta Popular, El Día El Cascabel, por citar algunos de los muchos existentes en aquella época. Esto estaría situándonos en el mismo contexto profesional en el que se movió Murguía - por ejemplo, fue director literario de La Ilustración Gallega y Asturiana desde enero de 1879-, lo que induce a pensar en una posible conexión personal que explicaría bien la petición bien el ofrecimiento de la colaboración de Rosalía referida en estas líneas. De hecho, ya en 1867 encontramos un punto de conexión entre Murguía y Manuel Ossorio, al reseñar este último el primer tomo de la Historia de Galicia (1865). Véase carta enviada por Ossorio al historiador y que está publicada en Barreiro \& Axeitos (2003: 494).

También este periodista le dedicó unas interesantes líneas a Rosalía en su enciclopedia de escritoras españolas. Véase Ossorio (1889).

${ }^{12}$ Con esa fecha hemos localizado dos, publicados en la Revista Europea, 13/10/1878, y en La Época, 5/10/1878. Igualmente un mes más tarde se anunciaba de la forma siguiente: "Almanaque de los niños para 1879. Año II. Redactado por distinguidos escritores y publicado por M. Ossorio y Bernard. Un tomo en $8 .^{\circ}$, con 40 láminas y una preciosa comedia para ser representada por niños. DOS REALES ejemplar en toda ESPAÑA" (La Correspondencia de España, 5/11/1878).

${ }^{13}$ El primer ejemplar de esta publicación madrileña se anunciaba así: "Almanaque de los niños para 1878, publicado por D. Manuel Ossorio y Bernard, y redactado por las Sras. Grassi, Maria de la Peña y Sinués (...) Recomendamos á las familias este nuevo libro, amenísimo, instructivo y moral. Consta de 160 págs. en $8^{\circ}$, y está ilustrado con graciosas viñetas, y se vende al ínfimo precio de dos reales en las principales librerías, y en casa del autor" (La Ilustración Española y Americana, 8/12/1877).

${ }^{14}$ Literalmente dice "redactado por las Señoras Castro de Murguía, Sinués y María de la Peña", a lo que le sigue la lista de colaboradores masculinos.
} 
situados en primer lugar y con un tipo de letra diferente a la usada en el rol restante de autores participantes en este número. Y resulta todavía más vistoso que sea el apelativo de la "señora Castro de Murguía" el que inicie la portada del Almanaque.

3.1. Documento bibliográfico inédito. Poema “¡Hijo mío!” de Rosalía de Castro

A continuación reproducimos en su totalidad la composición titulada "¡Hijo mío!" y que Rosalía dio a conocer dos años después de la inesperada y anticipada muerte de su hijo Adriano.

¡Hijo mío! ${ }^{15}$

No, no es posible que todo,

Todo haya acabado ya;

No acaba lo que es eterno,

No puede tener fin la inmensidad.

Algo ha quedado tuyo en mis entrañas

Que no morirá jamás,

Y que Dios, porque es justo y porque es bueno,

A desunir ya nunca volverá.

Tú te fuiste por siempre, mas mi alma

Te espera aun con amoroso afan,

Y vendrás, ó iré yo, bien de mi vida,

Allí donde nos hemos de encontrar.

En el cielo, en la tierra, en lo insondable,

Yo te hallaré y me hallarás....

¡No acaba lo que es eterno!

¡No puede tener fin la inmensidad!

ROSALÍA CASTRO DE MURGUÍA.

3.2. Sobre versiones del poema. De “¡Hijo mío!” a la composición iniciada por

"Era apacible el día" de En las orillas del Sar

Uno de los primeros análisis críticos pormenorizados de la composición "Era apacible el día" lo ha efectuado Marina Mayoral (1973), quien, tiempo después, se encargaría de elaborar una edición, también introducida y anotada por ella, del texto lírico En las orillas del Sar ${ }^{16}$. En el preámbulo de esta edición crítica se aludía a alguna parte de este poema a modo de ejemplo para contextualizar el análisis de la religiosidad de Rosalía de Castro, además de servir de base para realizar algún comentario de cariz estilístico sobre la obra lírica en cuestión.

\footnotetext{
${ }^{15}$ En Almanaque de los niños para 1879. Madrid: Establecimiento Tipográfico de E. Cuesta.

${ }^{16}$ Mayoral (1985).
} 
Otro crítico, Lázaro Carreter (1976), escogía precisamente el poema "Era apacible el día" para comentar el concepto de la función poética que otrora había teorizado el lingüista ruso Jakobson (1896-1982). A su vez, el estudio realizado por Carreter fue recogido por Alonso Montero (1985) en la selección de textos sobre Rosalía de Castro, puntualizando un poco más, en la sección de poemas de la eximia cantora comentados por otros.

Por su parte, en el trabajo realizado por Miller (1982) sobre las diferentes perspectivas manejadas en la evolución lírica de En las orillas del Sar, esta autora se servía del poema "Era apacible el día" para demostrar su hipótesis acerca de la variabilidad sensorial que puede causar una u otra creación rosaliana, en función del grado de connivencia del receptor con el poeta y el poema.

Continuando las pautas marcadas de esta trayectoria sobre el estado de la cuestión que aquí nos ocupa, igualmente resulta recomendable retomar la veta crítica de Marina Mayoral, quien, en otro estudio ${ }^{17}$ diferente al mencionado con anterioridad, realizaba un examen más detallado de "Era apacible el día".

Llegados a este punto y ya expuesta la materia prima fundamental a través de la que van elaborándose y nutriéndose estas líneas, se hace necesario seguir un itinerario interpretativo sobre el desarrollo de la ecdótica de este poema, algo que nos proporcionaría la posibilidad de aplicar una perspectiva crítica inusitada y llegar a conclusiones sobre el proceso creativo de esta elegía en la mente de Rosalía de Castro.

Por tanto es un privilegio tener al alcance las diferentes piezas del engranaje de ingeniería lírica de la de Compostela, algo que no es fácil que se dé, en tanto y cuanto siguen existiendo ingentes escollos en el estudio de su obra y de su vida.

Asumiendo la existencia de dos elementos esenciales para la construcción elegíaca como son la lamentación y la consolación, la versión de 1878 parece mostrar las etapas iniciales del duelo por la muerte de Adriano, negando la realidad ya desde el primer verso, "No, no es posible que todo," y concluyendo la composición con idéntica muestra de incredulidad a través de "¡No acaba lo que es eterno! / ¡No puede tener fin la inmensidad!".

Por su parte, la versión de 1882 semeja translucir el grado de desesperación de una madre que pierde a su hijo de poco más de un año de vida, puede que buscando encontrar una silenciosa resignación en las penumbras — no olvidemos que es el título del poema que publica en esa data- Y esta versión no difiere mucho de la de 1884, en la que acaso asomaría un conato de aceptación de la realidad, una asimilación tal vez legible a través del símbolo contrastivo que parece emanar desde el comienzo de la composición, "Era apacible el día / y templado el ambiente".

A continuación indicaremos con mayor detenimiento, además de éstas, otras cuestiones relativas a la ecdótica del poema.

\footnotetext{
${ }^{17}$ Mayoral (1986).
} 


\subsubsection{Versión de 1878}

La versión primitiva y diacrítica, es decir, los 16 versos que sirvieron de base para el texto titulado "Era apacible el día" y que Rosalía modificó e integró en la edición príncipe de En las orillas del Sar, apareció publicada en 1878 con el título “¡Hijo mío!” en el Almanaque de los niños para 1879. Se trataría, por tanto, de un texto autónomo que la reputada versificadora le dedicó a su hijo Adriano y que aparece transformado de forma notable en el poemario referido.

En este aspecto específico de la variabilidad textual lírica bien podría planear la sombra de la duda sobre una hipotética intervención de Murguía a tal efecto, acostumbrados como nos tiene a ser el artífice de la mutabilidad de genuinos textos de Rosalía, una fama ganada a pulso por el historiador con claras dotes para la manipulación textual y que ya demostraron otros, por ejemplo, Alonso (2000). Pero en el caso concreto que nos ocupa, en principio y hasta que se pruebe otra cosa diferente a lo que aquí se argumenta, parece ser que habría sido la misma Rosalía la responsable de renovar este poema, previamente impreso en el Almanaque madrileño, interviniendo directamente en la reinvención y la readaptación de estos versos elegíacos hasta conseguir la versión definitiva que se incluyó en En las orillas del Sar en 1884 y que comienza con el verso "Era apacible el día".

\subsubsection{Versión de $1882^{18}$}

La argumentación anterior parece adquirir mayor solidez y un resistente anclaje a lo verosímil, si se tiene en cuenta que Rosalía firmaba en Padrón la composición titulada "Penumbras"" y que se publicó en La Ilustración Cantábrica justo cuatro años después de haber dado a conocer el poema "¡Hijo mío!" del Almanaque, una versión corregida y aumentada respecto a la de 1878. En esta versión de 1882 acopló los 16 versos primitivos de 1878 en la tercera estrofa de la segunda parte de "Penumbras", pasando a ocupar los versos 21 a 36.

De tal manera, y dada la viabilidad de cotejar ambos textos, es una buena oportunidad para que el estudioso minucioso de la ecdótica rosaliana pueda comprobar que existen algunas variaciones entre estas dos versiones, es decir, la de 1878 y la de 1882, fundamentalmente las que atañen a la agrupación y colocación de estos versos elegíacos, y otras de detalle como las que especificamos a continuación:

\footnotetext{
${ }^{18}$ Incluida en el Apéndice de este artículo.

${ }^{19}$ Composición estructurada en nueve partes, cada una de ellas encabezada por el número romano correspondiente y cuyos versos iniciales son los detallados a continuación: "Los unos altísimos" (I), "Era apacible el día" (II), "Una luciérnaga entre el musgo brilla" (III), "Adivínase el dulce y perfumado" (IV), "Candente está la atmósfera;" (V), "Un manso rio, una vereda estrecha" (VI), "-Detente un punto, pensamiento inquieto" (VII), "Moría el sol, y las marchitas hojas" (VIII) y "Del rumor cadencioso de la onda" (IX). Las partes I, II y III se publicaron el día 18/5/1882, mientras que las restantes salieron a la luz el 28/5/1882.
} 
-Los versos 21 y 22 de 1882 dicen “¡Jamás! ¿Es verdad que todo / para siempre acabó ya?", mientras que en la versión de 1878 la poeta expresa "No, no es posible que todo, / Todo hay acabado ya;".

-Los versos 23 y 24 de 1882 manifiestan "No; no puede acabar lo que es eterno, / Ni puede tener fin la inmensidad.", y en 1878 "No acaba lo que es eterno, / No puede tener fin la inmensidad.".

-Los versos 25 a 28 de la versión de 1882 ocupan los versos 9 a 12 en 1878. También en el verso 25 después de "siempre;" se coloca un punto y coma, mientras que en 1878 se registra una coma después de "siempre," en el verso 9.

-En el verso 26 de 1882 aparece "aún" con acento gráfico frente a "aun" del verso 10 de la versión de 1878 .

-En el verso 27 de la composición de 1882 se suprime una coma tras "vendrás" que sí aparece después de "vendrás," en el verso 11 de 1878.

-En la versión de 1882 los versos 29 a 32 se corresponden con los versos 5 a 8 del poema publicado en 1878 .

-En el verso 33 de 1882 se suprime una coma después de "insondable".

-En el verso 34 de la versión de 1882 se coloca un punto tras "hallarás.", mientras que en la versión de 1878 se registran puntos suspensivos, "hallarás...".

-El verso 35 de 1882 es "No; no puede acabar lo que es eterno," en contraste con el verso 15 de 1878 que dice "¡No acaba lo que es eterno!”.

-El verso 36 de 1882 es "Ni puede tener fin la inmensidad.", mientras que en la versión de 1878 cierra la composición “¡No puede tener fin la inmensidad!”.

\subsubsection{Versión de $1884^{20}$}

La segunda parte del poema "Penumbras" de la versión publicada en La Ilustración Cantábrica de 1882 continuó el proceso de metamorfosis al que fueron sometidos los 16 versos iniciales de “¡Hijo mío!”. Esta vez el poema se incorporó a la que resultó ser la última obra publicada de Rosalía, es decir, En las orillas del Sar $\mathrm{y}$, a diferencia de las dos versiones precedentes, aparece sin título que le identifique, a excepción, claro está, del primer verso "Era apacible el día".

Una voz crítica, advirtiendo de estas variantes, valoraba como algo positivo los retoques realizados en algunos de estos versos, "mejorándolos positivamente" (Cordero 1950: 241). Asimismo señalaba el mismo crítico algunas variaciones de esta versión respecto a la anterior, es decir, la de 1882, si bien no registró todas tal y como señalaba Mayoral (1985) en su edición de En las orillas del Sar.

Esta versión fue, en cierto sentido, oficializada a lo largo del tiempo y casi siempre tenida en cuenta como la más pura y afín al estilo de Rosalía, tanto en la preparación de las ediciones críticas ${ }^{21}$ como también en las no críticas del postrero poemario rosaliano.

\footnotetext{
${ }^{20}$ Incluida en el Apéndice de este artículo.

${ }^{21}$ En la edición de Alonso Montero (2000) de En las orillas del Sar se anotan las principales variaciones de la versión de 1882 y la versión de 1884. Véase Alonso (2000: 72-73)
} 


\subsubsection{Versión de $1953^{22}$}

Este poema lo publicó Naya Pérez, quien se refería a que entre los manuscritos de Rosalía recaídos en sus manos existían algunos que ofrecían "aspectos interesantes (Naya 1953: 61). Aludía a dos composiciones independientes recogidas más tarde en En las orillas del Sar, una titulada "¡Tierra!"23 y otra "que sólo es un fragmento" y en la que "se advierten no sólo las variantes a que nos referimos, sino también un trastrueque en el orden que primitivamente pensó seguir Rosalía" (Naya 1953: 62).

Paradójicamente se trata del texto que más se asemeja al publicado en 1878. De hecho, si comparamos ${ }^{24}$ las dos versiones, la de 1878 y la de 1953 , las diferencias son mínimas, pero no por ello deben ser omitidas. La primera y más visible es la relativa a la supresión del título “¡Hijo mío!” y que sí aparecía en la versión del Almanaque de 1878. La segunda más notoria es la estructuración de los 16 versos en cuatro estrofas de cuatro versos cada una de ellas y que en la versión del Almanaque se exponían sin ningún tipo de agrupación. Otras desemejanzas entre los dos textos son las siguientes:

-Al final del verso 1 se omite una coma después de "todo" que sí aparece en la versión de 1878.

-Al final del verso 2 aparecen dos puntos, mientras que en la versión de 1878 se registra punto y coma.

-Al final del verso 3 se omite una coma después de "eterno" que sí figura en la versión de 1878 .

-El verso 6 dice "Que no se morirá jamás", mientras que en la versión de 1878 se lee "Que no morirá jamás,".

-Al final del verso 7 se suprime una coma después de "bueno" que sí está en la versión de 1878 .

-El "Tu" inicial del verso 9 se acentúa gráficamente en la versión de 1878.

-En el verso 10 se registran correctamente las palabras "aún" y "afán", mientras que en la versión de 1878 se muestran sin acento gráfico, es decir, "aun" y "afan,". También se cambia el adjetivo "cariñoso" por el de "amoroso".

-El verso 11 dice "Y vendrás o iré yo, bien de mi vida," frente al verso de la versión de 1878 "Y vendrás, ó iré yo, bien de mi vida,".

\footnotetext{
${ }^{22}$ Incluida en el Apéndice de este artículo.

${ }^{23}$ Con algunas variaciones, se corresponde con los versos 11 a 20 del poema que comienza "Era apacible el día" inserto en la edición príncipe de En las orillas del Sar.

${ }^{24}$ En la edición de Alonso Montero (2000) de En las orillas del Sar se incluye un Apéndice en el que aparece un cotejo diferente al realizado por nosotros aquí. Este crítico, con buen criterio en su momento, une las dos composiciones manuscritas que Naya publicó en 1953, es decir, la que comienza por "¡Tierra! sobre el cadáver" y la que se inicia con el verso "No, no es posible que todo", algo lógico puesto que, como hemos visto, en la versión de 1882 "Penumbras" de La Ilustración Cantábrica y en la versión de 1884 de la edición príncipe de En las orillas del Sar fue la propia Rosalía la que mutó los versos primitivos para integrarlos en una estructura lírica más amplia.
} 
-Alteración del orden de las palabras y omisión de una coma al final del verso 13 en la versión de 1953, "En la tierra, en el cielo, en lo insondable", en contraste con "En el cielo, en la tierra, en lo insondable," de la versión de 1878.

-Los versos 15 y 16 van sin exclamaciones "no acaba lo que es eterno / no puede tener fin la inmensidad", mientras que en la versión de 1878 leemos "¡No acaba lo que es eterno! / ¡No puede tener fin la inmensidad!”.

\section{Conclusiones}

Todo lo visto hasta el momento acerca del origen y progreso líricos del texto que se inicia con "Era apacible el día" podría estar permitiendo cierto grado de prerrogativa analítica a aquella persona que deba o quiera aproximarse a la ecdótica de este poema.

Así, mientras no se pruebe otra cosa, sintetizaríamos la vida lírica de "Era apacible el día" en base a tres fases de creación y subsiguientes renovaciones. El germen de la composición se hallaría en la versión de 1878, publicada en Madrid en el Almanaque de los niños para 1879 y que Rosalía rotuló “¡Hijo mío!”. Como una cadena de cuartetos, combinación métrica elegida por la vate en aquella ocasión, que transciende a otros ámbitos del contexto creativo como puede ser el cronológico - probablemente porque no puede tener fin la inmensidad del proyecto artístico-, cuatro años después Rosalía versionaba este poema y lo ampliaba, o lo fusionaba con otra composición, para pasar a ser la parte II del texto titulado "Penumbras" y que se publicó en el periódico madrileño La Ilustración Cantábrica en 1882. En ese momento desapareció por completo el título invocador a su hijo Adriano - “¡Hijo mío!”- Finalmente el poema continuó mutando en su tercera versión, en la edición príncipe de En las orillas del Sar de 1884. Ocupando el tercer lugar en el orden de colocación de los poemas, aparecía sin título y con el verso inicial "Era apacible el día".

Parece, pues, innegable que Rosalía quiso ir cincelando su poema en cada una de las versiones sucesivas hasta conseguir el resultado que hoy se puede leer en la primera edición de En las orillas del Sar, una composición creada por 42 versos, sin encabezamiento, cuyo primer verso es "Era apacible el día" y en la que los versos 23 a 36 tendrían su versión previa en el año 1878, concebidos en aquella ocasión como un mensaje literario autónomo y al que le dio el grito lírico desgarrador de "iHijo mío!”.

Con todo, habría que considerar también otra variante de este poema y que Naya Pérez desveló en 1953. El que fuera amigo del viudo e hijos de Rosalía, desde que la familia se había instalado en A Coruña, dio a conocer el poema partiendo del texto manuscrito por Rosalía, acaso una versificación en su estadio más legítimo e instintivo. No obstante quedaba una incógnita en el aire sobre un aspecto tan significativo como resulta ser la cronología de la composición.

Por nuestra parte, pensamos que es bastante probable que la versión presentada por Naya pudiera ser el borrador escrito de puño y letra por la autora antes de entregar el que salió publicado en 1878 en el Almanaque de los niños para 1879, 
hipótesis que cogería fuerza si se tiene en cuenta que son escasas las variaciones existentes entre los dos textos, el de 1878 que se aporta en este trabajo y el que Naya ofreció en 1953.

Por otro lado, interpretamos que, lejos de lo que pudiera parecer a simple vista, el poema titulado "¡Hijo mío!" no solo es el ostensible armazón que engloba una visible función conativa textual. En cierto sentido, si nos servimos en parte del concepto del formalismo ruso sobre la literariedad - literaturnost - , parece que el hecho trágico de la muerte de Adriano es el auténtico elemento dominante y núcleo de la función poética (Jakobson 1977) o estética (Mukarovski 1977) del texto, éste convirtiéndose así en portador de un íntimo mensaje artístico, a la par que único por ser motivo poético, explícito e implícito en toda la obra literaria de Rosalía de Castro.

También otra deducción a la que hemos llegado es la relativa a percibir un paralelismo entre la trayectoria diacrónica de la composición - a lo largo del sexenio de 1878 a 1884 y en el que una versión fue solapando a otra- y lo que parece ser el proceso de duelo lírico de la propia poeta (y madre). No habría que descuidar el detalle referente a que el texto, si bien tiene un sentido pleno en tanto y cuanto se ajusta a la función poética descrita por Jakobson - cotejable en las diversas reiteraciones, por ejemplo-, ésta principal, igualmente concede permisividad a la función expresiva - emotividad demostrable, por ejemplo, en el uso interjectivo-, lo que le confiere al texto versificado de 1878 un incremento ilustrativo, sobre todo, en el mensaje del distintivo "¡Hijo mío!”. De este modo, las interjecciones estarían mostrando toda una declaración de intenciones por parte del sujeto lírico, tal y como resulta ser el hecho de expresar con ímpetu una o varias emociones (dolor o queja por la pérdida del hijo) y que le estaría sirviendo de desahogo.

En cambio en la versión de 1882, el título se suprime y da la impresión de que la poeta quiera diluir parte de su dolor en la esfera de una sombra débil entre la luz y la oscuridad, no sabiendo muy bien dónde empieza la una o termina la otra. Lógicamente esas casi sombras son las penumbras. A parte de lo que afecta al ámbito de la creatividad en sí misma, habría que apreciar más si cabe el hecho circunstancial de que esta composición aporte, no solo el valor filológico, que sin duda lo tiene, sino también una plusvalía biográfica, creemos que de considerable repercusión, en el estudio de la vida y la producción literaria de Rosalía de Castro.

Ya por último, otra cuestión que resulta útil referir aquí, puesto que ha surgido al hilo de esta investigación, es la relativa a dar solución al misterio que Mayoral planteaba acerca de la publicación de algunos poemas en el periódico bonaerense La Nación Española ${ }^{25}$ y que, más tarde, constituyeron el poemario En las orillas del Sar. Esta crítica explicaba lo siguiente en su edición de este texto lírico:

[...] Rosalía no empieza a publicar en el citado periódico lo que serán después los poemas de En las orillas del Sar hasta octubre de 1882, y continúa hacién-

\footnotetext{
${ }^{25}$ Este periódico se imprimió por primera vez en 1880 y por última el 31 de octubre de 1883 . La mayor parte de esta publicación se nutría de las noticias de otros diarios argentinos, sintetizando muchas de ellas.
} 
dolo a lo largo de ese año y del siguiente. En esta edición se recogen los poemas que Rosalía publicó en dicho periódico hasta el 23 de octubre de 1883 . Ni en Galicia, ni en Madrid ni en Buenos Aires he podido encontrar los dos meses que faltan de ese año, ni los primeros de 1884, donde es casi seguro que se encontrarán más poemas (Mayoral 1985: 54).

Por nuestra parte, hemos podido averiguar que La Nación Española, periódico fundado por Manuel Vázquez Castro (1844-1885) ${ }^{26}$, anunciaba en su edición del 30 de octubre de 1883 que el día siguiente era el último en que salía a la calle con este nombre, pasando a fusionarse con la publicación el Correo Español ${ }^{27}$. La vida periodística de La Nación Española se extinguía el último día de octubre de 1883, de ahí la imposibilidad de encontrar los dos meses finales del año 1883 ni tampoco los iniciales de 1884.

\footnotetext{
${ }^{26}$ Posiblemente sea más conocido por Manuel Barros — segundo apellido paterno- . Nacido en Padrón (A Coruña), emigró bastante joven y estuvo viviendo en La Habana, Nueva York y Buenos Aires, todos ellos lugares en los que llevó a cabo una intensa labor periodística. Además de ser redactor de varias publicaciones, como por ejemplo del conocido periódico el Correo Español de Buenos Aires, fundó la Revista Galaica en 1879, de existencia corta, apenas un año. También ocupó la secretaría de la Sociedad Española de Beneficencia desde 1875 hasta 1884, y fue elegido primer presidente del Centro Gallego de Buenos Aires en 1879.

${ }^{27}$ Esta publicación de Buenos Aires salió a la luz en 1872 y se editó hasta 1905. En general, la línea editorial seguida fue de un especial interés por aquellas noticias relacionadas con España y, muy especialmente, de apoyo a los sectores antimonárquicos y republicanos.
} 


\section{Apéndice}

\section{Texto 1882}

(La Ilustración Cantábrica, 18/5/1882. Madrid)

\section{(PENUMBRAS)}

Era apacible el dia

Y templado el ambiente,

Y llovía, llovía,

Callada y mansamente;

Y mientras sordamente

Lloraba yo y gemía,

Mi niño, dulcemente,

Durmiendo se moría.

Al huir de este mundo, ¡qué sosiego en su frente!

Al verle yo alejarse, iqué borrasca en la mia!

Tierra sobre el cadáver insepulto

Antes que empiece á corromperse!... ¡tierra!

Ya el hoyo se ha cubierto, sosegaos,

Bien pronto en los terrones removidos

Verde y pujante crecerá la hierba.

¿Qué andais buscando en torno de las tumbas,

Torvo el mirar, nublado el pensamiento?

No os ocupéis de lo que al polvo vuelve;

Jamas el que descansa en el sepulcro

Ha de tornar á amaros ni á ofenderos.

¡Jamás! ¿Es verdad que todo

Para siempre acabó ya?

No; no puede acabar lo que es eterno,

Ni puede tener fin la inmensidad.

Tú te fuiste por siempre; mas mi alma

Te espera aún con amoroso afan,

Y vendrás ó iré yo, bien de mi vida,

Allí donde nos hemos de encontrar.

Algo ha quedado tuyo en mis entrañas

Que no morirá jamas,

$\mathrm{Y}$ que Dios, porque es justo y porque es bueno,

A desunir ya nunca volverá.

En el cielo, en la tierra, en lo insondable

Yo te hallaré y me hallarás.

No; no puede acabar lo que es eterno, 
Ni puede tener fin la inmensidad.

-Sí, sí, es verdad, ha partido

Para nunca más tornar.

No hay nada eterno para el hombre, huésped

De un dia, en este mundo terrenal,

En donde nace, vive y al fin muere

Cual todo nace, vive y muere acá.

\section{ROSALÍA CASTRO DE MURGUÍA}

\section{Texto 1884}

(En las orillas del Sar. Poesías. Madrid: Establecimiento Tipográfico de Ricardo Fé)

Era apacible el día

y templado el ambiente,

y llovía, llovía

callada y mansamente;

y mientras silenciosa

lloraba yo y gemía, mi niño, tierna rosa, durmiendo se moría.

$\mathrm{Al}$ huir de este mundo, iqué sosiego en su frente!

Al verle yo alejarse, ¡qué borrasca en la mía!

Tierra sobre el cadáver insepulto

antes que empiece a corromperse..., ¡tierra!

Ya el hoyo se ha cubierto, sosegaos;

bien pronto en los terrones removidos

verde y pujante crecerá la hierba.

¿Qué andáis buscando en torno de las tumbas, torvo el mirar, nublado el pensamiento?

¡No os ocupéis de lo que al polvo vuelve!

Jamás el que descansa en el sepulcro

ha de tornar a amaros ni a ofenderos,

¡Jamás! ¿Es verdad que todo

para siempre acabó ya?

No, no puede acabar lo que es eterno, ni puede tener fin la inmensidad.

Tú te fuiste por siempre; mas mi alma

te espera aún con amoroso afán, 
y vendrás o iré yo, bien de mi vida, allí donde nos hemos de encontrar.
Algo ha quedado tuyo en mis entrañas que no morirá jamás, y que Dios, porque es justo y porque es bueno, a desunir ya nunca volverá.
En el cielo, en la tierra, en lo insondable yo te hallaré y me hallarás.
No, no puede acabar lo que es eterno, ni puede tener fin la inmensidad.
Mas..., es verdad, ha partido para nunca más tornar.
Nada hay eterno para el hombre, huésped de un día, en este mundo terrenal, en donde nace, vive y al fin muere, cual todo nace, vive y muere acá.

\section{Texto $1953^{28}$}

(NAYA PÉREZ, Juan: Inéditos de Rosalía. Santiago de Compostela: Patronato Rosalía de Castro)

¡Tierra! sobre el cadáver,

Antes que empiece a corromperse, ¡tierra!

Ya el hoyo se ha cubierto... consolaos,

Pronto ahora en la escoria removida,

Verde y pujante crecerá la hierba.

¿Mas dónde está el que fue? ¿Sabéis acaso

Que ha sido de él? ¡Ah, necios!

No os ocupéis de lo que al polvo vuelve;

¿Qué importan los cadáveres, que importan

Cuando algo más que la materia ha muerto?

No, no es posible que todo

\footnotetext{
${ }^{28}$ Naya las dio a conocer como dos composiciones independientes: "Como particularidad hay que registrar que el nombre de su creadora figura al pie de la que comienza '¡Tierra!', y en la siguiente, que sólo es un fragmento, se advierten no sólo las variantes a que nos referimos, sino también un trastrueque en el orden que primitivamente pensó seguir Rosalía” (Naya 1953: 61-62).
} 
Todo haya acabado ya:

No acaba lo que es eterno

No puede tener fin la inmensidad.

Algo ha quedado tuyo en mis entrañas

Que no se morirá jamás

Y que Dios, porque es justo y porque es bueno

A desunir ya nunca volverá.

Tu te fuiste por siempre, mas mi alma

Te espera aún con cariñoso afán

Y vendrás o iré yo, bien de mi vida,

Allí donde nos hemos de encontrar.

En la tierra, en el cielo, en lo insondable

Yo te hallaré y me hallarás...

No acaba lo que es eterno

No puede tener fin la inmensidad.

\section{Referencias bibliográficas}

ALONSO MONTERO, Xesús (1985): En torno a Rosalía. Madrid: Júcar. (2000): Edición de En las orillas del Sar. Madrid: Cátedra.

BARREIRO FERNÁNDEZ, Xosé Ramón \& Xosé Luís AXEITOS (2000): Manuel Murguía. Vida e obra. Vigo: Xerais. Maza. (2003): Cartas a Murguía I. A Coruña: Fundación Pedro Barrié de la (2005): Cartas a Murguía II (1868-1885). A Coruña: Fundación Pedro Barrié de la Maza.

BOUZA-BREY, Fermín (1962): “Adriano y Valentina, motivaciones inspiradoras de Rosalía de Castro". Cuadernos de Estudios Gallegos 17, número 53: 374390.

CARBALLO CALERO, Ricardo (1964): "Bibliografía rosaliana". Grial 3: 119121.

(1979): Estudos rosalianos. Aspectos da vida e da obra de Rosalía de Castro. Vigo: Galaxia.

CARRÉ ALDAO, Eugenio (1926-1927): "Estudio bio-bibliográfico crítico acerca de Rosalía de Castro". Boletín de la Real Academia Gallega 16, número 186: 131-135.

CASTRO, Rosalía de (1878): “Hijo mío!”. Almanaque de los niños para 1879. Madrid: Establecimiento Tipográfico de E. Cuesta. (1882): "Penumbras". La Ilustración Cantábrica. Madrid, 18/5 y 28/5.

(1993): Obras completas de Rosalía de Castro, edición de Marina Mayoral. Madrid: Turner, 2 vols. 
CORDERO CARRETE, Felipe (1950): "Variantes en un poema de Rosalía". Cuadernos de Estudios Gallegos 5, número 16: 241-245.

El Diario de Santiago (1874): "Movimiento literario en Galicia". Santiago de Compostela, 15/6. (1876): "Sección local". Santiago de Compostela, 6/11.

El Heraldo Gallego (1874): "Variedades". Ourense, 29/1.

El Imparcial (1876): "Sección Noticias". Madrid, 2/10.

ESTRADA NÉRIDA, Julio (1983): Páginas de una biografía: Manuel Murguía, director del Archivo de Simancas (1868-1870). Sada (A Coruña): Do Castro.

FERNÁNDEZ BAJÓN, María Teresa (2001): "Disposiciones legislativas sobre políticas de archivos y bibliotecas en la España del siglo XIX" [en línea], en Documentación de las Ciencias de la Información, número 24, 45-77. En: www.ucm.es/BUCM/revistas/inf/02104210/articulos [Consulta: 8 de septiembre 2011]. ISSN 0210-4210.

GARCÍA MARTÍ, Victoriano (1977): “Rosalía de Castro o el dolor de vivir", in Obras completas de Rosalía de Castro, Victoriano García Martí (ed.), tomo I, pp. XI-CCL. Madrid: Aguilar.

GONZÁlEZ BESADA, Augusto (1916): Rosalía Castro. Notas biográficas. Madrid: Biblioteca Hispania.

La Época (1878): “Anuncios". Madrid, 5/10.

JAKOBSON, Roman (1977): Ensayos de poética. Madrid: F.C.E.

La Correspondencia de España (1878): "Anuncios". Madrid, 5/11.

La Ilustración Española y Americana (1877): “Libros presentados á esta redacción por autores ó editores". Madrid, 8/12.

LAFOLLETTE MILLER, Martha (1982): “Aspects of Perspective in Rosalía de Castro's En las orillas del Sar". Kentucky Romance Quarterly 29: 273-282.

Las Provincias (1876): "Noticias". Valencia, 24/9.

LÁZARO CARRETER, Fernando (1976): Estudios de poética. Madrid: Taurus.

LÓPEZ, Aurora \& Andrés POCIÑA (1991): Rosalia de Castro. Documentación biográfica y bibliografia crítica (1837-1990), vol. I (1837-1940). A Coruña: Fundación Pedro Barrié de la Maza.

MARTÍNEZ MURGUÍA, Manuel (1866): Historia de Galicia, tomo I. Lugo: Soto Freire.

MAYORAL, Marina (1973): Poesía española contemporánea. Madrid: Gredos. - (1985): Edición de En las orillas del Sar. Madrid: Castalia. (1986): Rosalía de Castro. Madrid: Cátedra.

MOAR, José María (1920): "Negra sombra”. El Compostelano. Santiago de Compostela, $1 / 6$.

MUKAROVSKI, Jan (1977): Escritos de Estética y Semiótica del Arte. Barcelona: Gustavo Gili.

NAYA PÉREZ, Juan (1974): "El final de una estirpe: Rosalía de Castro y Manuel Murguía”. Boletín Real Academia Gallega 31, número 356: 25-49. 
(1998): Estudios acerca de la familia Murguía-Castro. A Coruña: Diputación Provincial de A Coruña.

OSSORIO Y BERNARD, Manuel (1889): "Apuntes para un diccionario de escritoras españolas del siglo XIX”. La España Moderna. Madrid, septiembre.

POCIÑA, Andrés \& Aurora LÓPEZ (2000): Rosalía de Castro. Estudios sobre a vida e a obra. Santiago de Compostela: Laiovento.

Revista de Archivos, Bibliotecas y Museos (1876a): "Noticias". Madrid, 20/5. (1876b): "Noticias". Madrid, 20/9.

Revista Europea (1878): "Bibliografía”. Madrid, 13/10.

ROLDÁN, Manuel (1949): "La hija de Rosalía Castro evoca en una clínica de La Coruña varios sucesos de su vida". La Noche. Santiago de Compostela, 9/4 